\title{
Plagiarism and its implications: Common terminology identification in scientific papers
}

By Gislene Farias de Oliveira. Editor in Chief ${ }^{1}$

Almost all over the world, especially in European countries such as Ingleterra, the appropriation of ideas, words and images of one person, by another inadvertently and without due credit, is considered a practice widely repudiated, especially in higher education. Even a small part of your manuscript that contains plagiarism, can have serious consequences, either in insufficient allocation of notes or even expulsion from the university.

The United States is another example, where the practice of plagiarism is regarded as very serious, and also subject to academic penalties. Authors such as John Edlund of California State University consider that plagiarism directly violates intellectual honesty and as such is open to investigations by research funding agencies in several countries.

In scientific research, it has been applied all the necessary rigor when they happen allegations of plagiarism in academic publications. It is a policy of no tolerance for such practices, which has been adopting through national and international journals. Except in major journals, more detailed information on the issues surrounding plagiarism and ethics related to the scientific article is not yet available. And neither are the punishments so severe, even being accused of plagiarizing the authors, with the punishment no longer be able to submit their work to this or that journal.

There is a great deal of attention given to issues involving plagiarism in universities and also in research funding systems. Although, countries such as China, Singapore and Korea do not share this same view on intellectual property, that is, authorship and originality are not as valued as in the Occident.

The traditional notion of intellectual property in these countries is more collective than individual. Thus, in a multicultural context, there are many conflicts and possible ethical dilemmas arising from the view on the authorship and textual production. It is necessary to develop educational mechanisms and strategies, capable of minimizing such differences, regarding the vision of the text of the scientific article.

In Brazil little is discussed about plagiarism in science. Perhaps not because of the 
absence of the problem in the country, but because of the lack of initiatives that seek to deepen discussions about this issue.

In summary, the discussion about the dimensions of the plagiarism practice, particularly in academic is valuable contribution to scientific activity. Given the relevance of this topic would be naive, not seek to discuss pragmatically, plagiarism in universities, as well as in the various other research institutions. This includes postgraduate programs.

Further guidance on such a practice should be present in educational policies and in various postgraduate programs. Joint actions tend to be more effective in their purposes.

${ }^{1}$ PhD in Social Psychology, Federal University of Paraíba, Brazil. Post Doctorate in Health Sciences from ABC Medicine School - São Paulo, Brazil. Professor at the Federal University of Cariri, Ceará, Brazil. Contact: gislenefarias@ gmail.com 